\title{
The Anchoring of Inflation Expectations in the Short and in the Long Run
}

\author{
Dieter Nautz* \\ Aleksei Netsunajev* \\ Till Strohsal*
}

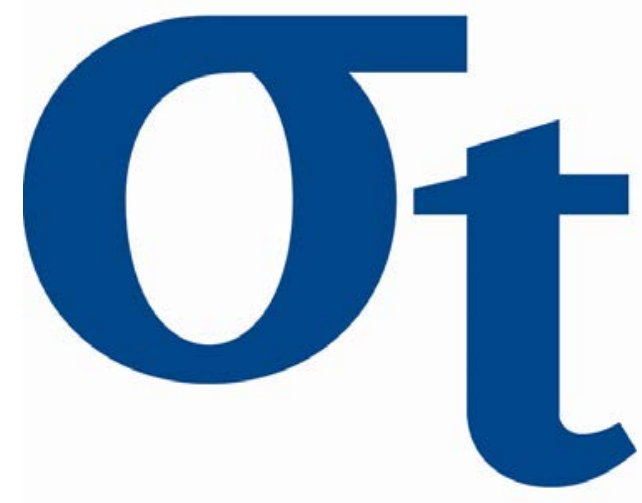

9

寸

6

m

* Freie Universität Berlin, Germany

This research was supported by the Deutsche Forschungsgemeinschaft through the SFB 649 "Economic Risk".

http://sfb649.wiwi.hu-berlin.de ISSN 1860-5664 


\title{
The Anchoring of Inflation Expectations in the Short and in the Long Run
}

\section{Dieter Nautz, Aleksei Netšunajev and Till Strohsal* \\ Freie Universität Berlin, Department of Economics}

\begin{abstract}
March 16, 2016
This paper introduces structural VAR analysis as a tool for investigating the anchoring of inflation expectations. We show that U.S. consumers' inflation expectations are anchored in the long run because macro-news shocks are long-run neutral for long-term inflation expectations. The identification of structural shocks helps to explain why inflation expectations deviate from the central bank's target in the short run. Our results indicate that the recent decline of long-term inflation expectations does not result from deanchoring macro-news but can be attributed to downward adjustments of consumers' expectations about the central bank's inflation target.
\end{abstract}

Keywords: Inflation Expectations, Michigan Survey, Structural VAR, Markov-Switching Heteroskedasticity

JEL classification: E31, E52, E58

*Financial support from the Deutsche Forschungsgemeinschaft (DFG) through CRC 649 "Economic Risk" is gratefully acknowledged. We are grateful for comments by Sven Schreiber, Mathias Trabandt, and Lars Winkelmann. E-mail: dieter.nautz@fu-berlin.de; aleksei.netsunajev@fu-berlin.de; till.strohsal@fu-berlin.de; Phone: +49 (0)30 838-53399 (Till Strohsal). 


\section{Introduction}

There is a growing consensus among both, academics and central bankers, that the analysis of the determinants and the behavior of inflation expectations is of crucial importance for the conduct of monetary policy. Long-term inflation expectations, taken from surveys or calculated from inflation-indexed bonds, are closely monitored by financial markets and are a key indicator for the credibility of a central bank and its inflation target (see e.g. Yellen, 2015). Central banks increasingly explain their policy decisions with the development of inflation expectations and the need to keep them well-anchored. It is not obvious, however, how to empirically measure the degree to which inflation expectations are (de-) anchored.

The empirical literature on inflation expectations typically assumes that well-anchored expectations should not respond to macroeconomic news that have no implications for the long run. More precisely, while short-run oriented macro-news may change short-term inflation expectations, they should have no significant impact on firmly anchored long-term inflation expectations. Following Gürkaynak et al. (2010), many event studies employ news-regressions taking the surprise component of macroeconomic announcements as an empirical proxy for macro-news. In this literature, it is assumed that any response of long-term inflation expectations to macro-news indicates de-anchored inflation expectations (see e.g. Ehrmann, 2015, Nautz and Strohsal, 2015 and the literature cited therein). 
News-regressions focus on the immediate effect of macro-news on the announcement day. However, ignoring the dynamics of inflation expectations may result in misleading conclusions about the degree of anchoring. On the one hand, the credibility problem of a central bank is exaggerated if the response of inflation expectations to a data surprise actually dies out quickly. On the other hand, if the effect of a shock on inflation expectations is highly persistent, the de-anchoring problem is probably more severe than the shortrun reaction of expectations seems to suggest.

This paper proposes a dynamic perspective on inflation expectations that is able to distinguish between short-run and long-run effects of shocks. To that aim, we assume that inflation expectations are driven by two types of structural shocks. In line with the earlier literature, the first structural shock is the macro-news shock. Advancing on standard news-regressions, however, macro-news shocks not only include surprises in data releases for unemployment, inflation or output. They refer to all sources of new information about short-term macroeconomic developments. Accordingly, macro-news shocks should be closely related to short-term inflation expectations. However, the more important macro-news shocks are for long-term inflation expectations, the weaker is the anchoring of inflation expectations. Therefore, we define inflation expectations to be anchored in the long run, if the impact of macronews shocks on long-term inflation expectations is only transitory. In the spirit of Blanchard and Quah (1989), this new anchoring criterion is implemented by a long-run neutrality restriction for macro-news shocks in a structural VAR 
model. The validity of the long-run anchoring restriction is tested by exploiting the heteroskedasticity in the data (see Lanne et al., 2010). Yet, even long-run neutral macro-news shocks may de-anchor long-term inflation expectations in the short run. Therefore, we propose to measure the degree of short-run deanchoring by the relative importance of macro-news shocks for the variance of long-term inflation expectations.

In addition to short-run oriented macro-news shocks, we also consider the impact of long-run oriented target shocks on inflation expectations. This second structural shock refers to monetary policy strategy, including the central bank's long-run inflation target. The identification of macro-news and target shocks implies that inflation expectations adjust for two reasons. First, they may change in response to a target shock indicating that the public adjusted its expectations about the central bank's inflation target. In this case, expectations may still be anchored but at a new level. Second, long-term inflation expectations may change in response to macro-news shocks. In this case, inflation expectations are de-anchored - at least in the short run.

Our results can be summarized as follows. Using the Michigan Survey of consumer's inflation expectations from 1990 onwards, we find that the longrun neutrality restriction of macro-news shocks is supported by the data. Therefore, we conclude that U.S. consumers' inflation expectations are anchored in the long run. However, anchoring is not complete and the disturbing impact of macro-news shocks on long-term inflation expectations is far from negligible. Particularly in times of high volatility, macro-news shocks explain 
about $14 \%$ of the variance of long-term inflation expectations. In the aftermath of the financial crisis, there has been a small but disconcerting decline of consumers' long-term inflation expectations. According to a counterfactual analysis, this decline of expectations does not result from de-anchoring macronews. Rather, long-term inflation expectations decreased in response to target shocks indicating that consumers adjusted their expectations about the central bank's inflation target downwards.

The rest of the paper is structured as follows. In the next section we briefly review the alternative approaches used in the empirical literature on inflation expectations anchoring in order to elaborate on the distinguishing features of the structural VAR approach. Section 3 introduces the structural VAR model, discusses the economics behind the identifying long-run restriction and shows how to test for long-run anchoring using the observed heteroskedasticity in the expectations data. Section 4 describes the Michigan Survey data on inflation expectations. Section 5 presents the empirical results and the counterfactual analysis. Finally, Section 6 offers some concluding remarks. 


\section{The Anchoring of Inflation Expectations}

\subsection{Well-Anchored Inflation Expectations: A Theoretical Perspective}

The key role of inflation expectations for monetary policy practice originates from one of the most prominent results from modern macroeconomic theory: the forward-looking Phillips curve. Since wage and price setting crucially depend on the expectations of future inflation, controlling inflation boils down to controlling inflation expectations. Standard New Keynesian DSGE models, either purely forward-looking ones (Clarida et al., 2000) or modifications with backward-looking and rules of thumb (Rudebusch, 2001), typically have strong implications about the long-run dynamics of inflation expectations. Particularly, in case of a fully credible and transparent central bank with a clearly communicated inflation target, rational inflation expectations should be wellanchored. Given this scenario, the effect of shocks should die out quickly and have no long-run impact on the level of long-term inflation expectations. When shocks do have a significant and persistent impact on long-term inflation expectations, this indicates a lack of credibility and de-anchored inflation expectations (see Bomfim and Rudebusch, 2000). 


\subsection{News-Regressions and the Anchoring of Inflation Expectations in the Very Short Run}

In accordance with theoretical predictions, estimating the responsiveness of inflation expectations to macroeconomic surprises has become the standard approach to investigate the anchoring of inflation expectations empirically. Macroeconomic surprise variables are usually calculated from surveys of professional or consumer forecasts. The news component of a macroeconomic announcement is defined as the difference between the expected and the realized value of a variable. Following Gürkaynak et al. (2010), many empirical contributions performed news-regressions to investigate whether inflation expectations are unaffected by macro-news on the announcement day. The overall picture provided by this literature is that U.S. long-term inflation expectations tend to show signs of de-anchoring, particularly during the recent financial crisis (see Beechey et al., 2011, Galati et al., 2011, Autrup and Grothe, 2014, Bauer, 2015 and Nautz and Strohsal, 2015). ${ }^{1}$

News-regressions have to assume that the set of macro-surprise variables under consideration is complete. Whenever a news-regression indicates anchored inflation expectations, there is the risk that expectations do not respond only because a relevant surprise variable has been omitted. Moreover, since macro-surprises can only occur on the days of data releases, news-regressions

\footnotetext{
${ }^{1}$ For the Euro area, Ehrmann et al. (2011) show that the introduction of the Euro led to a substantial increase in the anchoring of long-term inflation expectations in the pre-crisis period, particularly in Italy and Spain. More recent evidence on inflation expectations anchoring in the Euro area is provided by Ehrmann (2015) and Pagenhardt et al. (2015).
} 
restrict the attention to the immediate response of inflation expectations to news. Therefore, news-regressions investigate the anchoring of inflation expectations in the very short run. They are not designed to capture the complex dynamics and adjustment processes of inflation expectations data. As a consequence, results from news regressions tend to exaggerate the degree of de-anchoring if the estimated response to news actually dies out quickly. By contrast, the credibility problem of the central bank is underestimated if the estimated response of inflation expectations to news turns out to be highly persistent.

\subsection{The Anchoring of Inflation Expectations: A Dynamic Perspective}

Mehrotra and Yetman (2014), Strohsal and Winkelmann (2015) and Strohsal et al. (2016) investigate the anchoring of inflation expectations from a more dynamic perspective. This literature shares the notion that long-term inflation expectations, pushed away from the inflation target by a shock, are still anchored as long as they eventually return to the inflation target. The less persistent the effect of the shock (the faster inflation expectations return to the target), the stronger the anchoring. The problem of this strand of the anchoring literature is that the results are based on univariate reduced form equations. Since the estimated reduced form shocks are not structural, the response of inflation expectations cannot be interpreted economically. 
This paper builds on the dynamic anchoring criterion and proposes a more structural approach to assess the anchoring of inflation expectations. Instead of estimating a univariate reduced form equation, we employ a bi-variate structural VAR model of short- and long-term inflation expectations. The structural VAR approach has two distinguishing features. First, a bi-variate VAR accounts for the interaction between inflation expectations of different horizons. In fact, there is evidence that spillovers from short-term to long-term expectations are an important source of de-anchoring (see e.g. Jochmann et al., 2010). Second, a structural VAR overcomes the interpretation problems of reduced form models. The identification of structural macro-news and target shocks allows to shed more light on the economics behind an observed change of inflation expectations. In the following section, we briefly describe the structural VAR model and discuss the long-run restriction required for the identification of the structural shocks which drive the dynamics of short- and long-term inflation expectations. 


\section{A Structural VAR Model of Inflation Expectations}

\subsection{The Structural VAR}

Consider the reduced form VAR of order $p$ :

$$
y_{t}=v+A_{1} y_{t-1}+\cdots+A_{p} y_{t-p}+u_{t},
$$

where $y_{t}=\left(y_{1 t}, \ldots, y_{K t}\right)^{\prime}$ is a vector of observable variables, the $A_{i}$ 's are $(K \times K)$ coefficient matrices, $v$ is a $(K \times 1)$ constant term and the $u_{t}$ 's are $K$ dimensional serially uncorrelated residuals with mean zero and non-singular covariance matrix $\Sigma_{u}$. In our application we have $K=2$ while $y_{1 t}, y_{2 t}$ refer to short-term and long-term inflation expectations, respectively.

Since the reduced form residuals $u_{t}$ in (1) are contemporaneously correlated, they do not allow for an economic interpretation. The uncorrelated structural shocks $\varepsilon_{t}$, which do have an economic meaning, are obtained from the reduced form residuals by a linear transformation:

$$
\varepsilon_{t}=B^{-1} u_{t} \quad \text { or } \quad u_{t}=B \varepsilon_{t}
$$

The matrix $B$ contains the instantaneous effects of the structural shocks on the observed variables. Different structural models lead to the same reduced form. In general, it can be shown that the (exact) identification of the structural shocks requires $\frac{K(K-1)}{2}$ restrictions. Therefore, we need only one restriction for 
identifying the two structural shocks of a bi-variate SVAR of short- and longterm inflation expectations $(K=2)$.

There are several types of restrictions prevalent in the empirical literature. The short-run restrictions are imposed directly on $B$ to make it unique. Typically, these restrictions are zero restrictions indicating that a certain shock does not have an instantaneous impact on one of the variables (Sims, 1980). Following Blanchard and Quah (1989), the other type of restrictions refers to the long-run effects of a structural shock. Recall that the long-run effects of structural shocks are given by

$$
\Xi_{\infty}=\left(I_{K}-A_{1}-\cdots-A_{p}\right)^{-1} B
$$

In our application, the dynamics of short-term and long-term inflation expectations are determined by two types of shocks: i) macro-news shocks and ii) target shocks. In the following section, we discuss these structural shocks in more detail and introduce the long-run restriction used for identification.

\subsection{Identifying Macro-News and Target Shocks}

In line with the empirical literature on inflation expectations anchoring, the first type of shock is the macro-news shock. This structural shock advances on the surprise variables used in the news-regression literature. In particular, macro-news shocks should have no long-run impact on well-anchored longterm inflation expectations. This dynamic and structural anchoring criterion 
can be implemented empirically by a long-run neutrality restriction for the response of long-term inflation expectations to macro-news shocks. Specifically, we assume that the accumulated response of month-on-month changes in long-term expectations to macro-news shocks is zero. This long-run restriction can be visualized in the following way:

$$
\Xi_{\infty}=\left[\begin{array}{ll}
* & * \\
0 & *
\end{array}\right] .
$$

The second type of shock which is identified by the long-run restriction is the target shock. Target shocks refer to the long-run strategy of the central bank. In particular, they capture the impact of news on consumers' beliefs upon the level of the long-run inflation target. Obviously, target shocks should have significant effects on long-term inflation expectations both in the short and in the long run. By contrast, the role of target shocks for short-term inflation expectations should only be small.

In the following section, we briefly review how to test the validity of the identifying long-run restriction by exploiting the heteroskedasticity in the data.

\subsection{Testing Identifying Restrictions Using Volatility Regimes}

Lanne et al. (2010) and Herwartz and Lütkepohl (2014) propose and develop structural VARs with a Markov regime switching mechanism for modeling 
volatility changes and identifying structural shocks. This approach is very useful for our analysis as it overidentifies the SVAR and, therefore, allows us to test the validity of the long-run anchoring restriction imposed on $\Xi_{\infty}$.

Consider the reduced form VAR from (1)

$$
y_{t}=v+A_{1} y_{t-1}+\cdots+A_{p} y_{t-p}+u_{t}
$$

where the distribution of the error term $u_{t}$ depends on a discrete Markov process $s_{t}(t=0,1,2, \ldots)$ with regimes $1, \ldots, M$, and transition probabilities

$$
p_{i j}=\operatorname{Pr}\left(s_{t}=j \mid s_{t-1}=i\right), \quad i, j=1, \ldots, M \text {. }
$$

The conditional distribution of $u_{t}$ given $s_{t}$ is assumed to be normal with regime dependent covariance matrices:

$$
u_{t} \mid s_{t} \sim N\left(0, \Sigma_{u}\left(s_{t}\right)\right)
$$

Under these assumptions, identification is achieved by using the following decomposition of the covariance matrices:

$$
\Sigma_{u}(1)=B \Lambda_{1} B^{\prime}, \quad \Sigma_{u}(m)=B \Lambda_{m} B^{\prime}, \quad m=2, \ldots, M,
$$

with $\Lambda_{m}=\operatorname{diag}\left(\lambda_{m 1}, \ldots, \lambda_{m K}\right)$. In this setup, the matrix of impact effects, $B$, is uniquely determined if for any subscripts $k, l \in\{1, \ldots, K\}, k \neq l$, there is a $j \in\{2, \ldots, M\}$ such that $\lambda_{j k} \neq \lambda_{j l}$ (Lanne et al., 2010, Proposition 1). The 
variances of all structural shocks are normalized to be one in the first volatility regime, i.e. $\Lambda_{1}=I_{K}$. Therefore, the diagonal elements of $\Lambda_{m}, m=2, \ldots, M$ can be interpreted as the variances of shocks in regime $m$ relative to the first regime.

We follow the procedure of Herwartz and Lütkepohl (2014) to estimate the model with numerical maximum likelihood. To obtain confidence intervals for impulse responses we use fixed design wild bootstrap as done by Lütkepohl and Netšunajev (2014) and Chen and Netšunajev (2016).

\section{Data: The Michigan Survey of Consumers' Inflation Expectations}

Survey measures contain valuable information and should serve as important benchmarks for the assessment of inflation expectations. ${ }^{2}$ The Michigan Survey of Consumers reports short-term and long-term inflation expectations. A balanced sample of monthly data is available from 1990M4 to 2015M12, providing 309 observations. We use median values of expected inflation rates.

Inflation expectations from the Michigan Survey are of two different horizons: 12 months $\left(\pi_{t}^{e, s}\right)$ and 5 to 10 years $\left(\pi_{t}^{e, l}\right)$. Specifically, the questionnaire of the survey asks:

By about what percent do you expect prices to go (up/down) on the average, during the next 12 months?

\footnotetext{
${ }^{2}$ Recent studies employ surveys to learn more about the rationale behind individual forecasts (Schmidt and Nautz, 2012, Easaw et al., 2013) as well as the determinants (Dovern et al., 2012) and the information content (Dovern, 2015) of forecaster disagreement.
} 
and

By about what percent per year do you expect prices to go (up/down) on the average, during the next 5 to 10 years?

In forming these two expectations, consumers will clearly weight available bits of information in different ways. Short-term expectations are based first and foremost on current macroeconomic developments and should be particularly responsive to macro-news shocks. By contrast, long-term expectations should be predominantly affected by information about the long run and, thus, by target shocks.

Figure 1 Short-Term and Long-Term Inflation Expectations in the U.S.

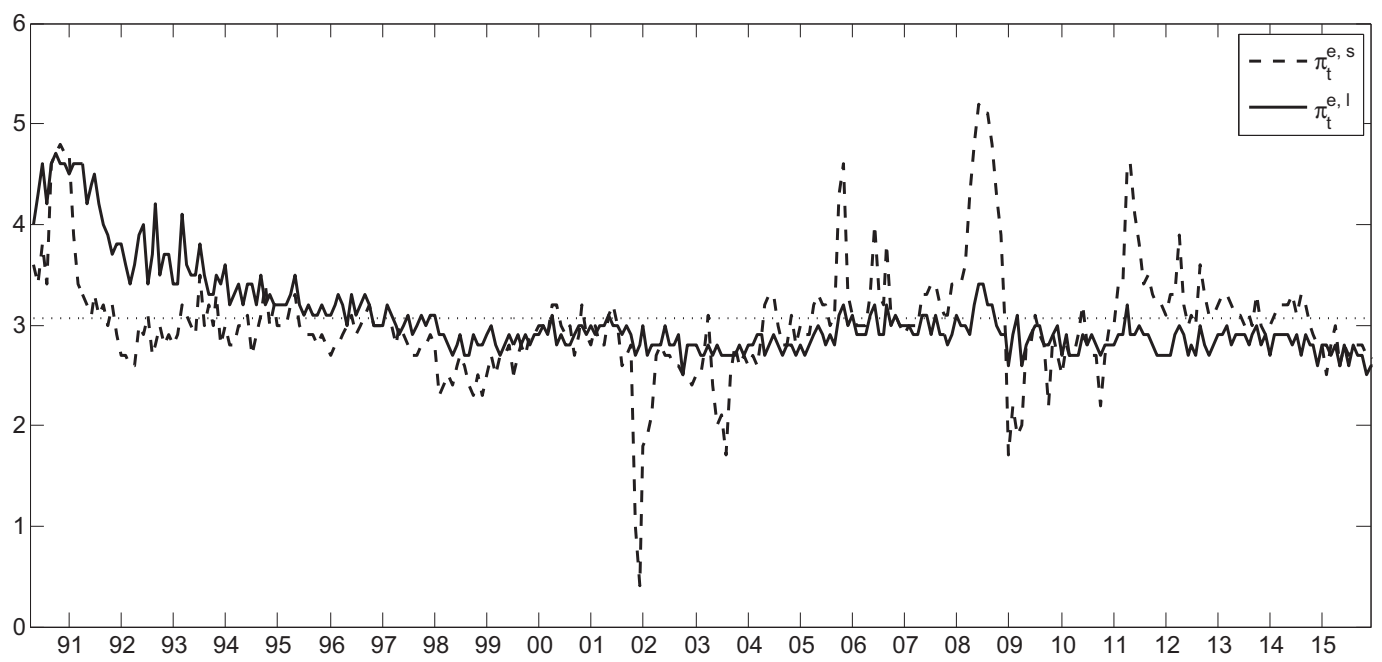

Source: Michigan Survey of consumers' inflation expectations with horizons of up to one year and 5 to 10 years. Sample period 1990M4 to 2015M12.

The time series of short-term and long-term inflation expectations are shown in Figure 1. Note that the averages of both expectation series are about 3\% which is close to the long-run average of actual inflation over the sample period. 
The results of unit root tests shown in Table 1 suggest that consumers' shortterm inflation expectations are stationary. In contrast, long-term inflation expectations exhibit much more persistence. Irrespective of the unit root test applied, there is clear empirical evidence that long-term inflation expectations should be treated as a non-stationary time series. ${ }^{3}$ In accordance with the bulk of the empirical anchoring literature, we therefore take the change of long-term inflation expectations as the dependent variable (and not the level). Following e.g. Del Negro et al. (2015), the non-stationarity of long-term inflation expectations data can be explained by a time-varying but highly persistent long-run inflation target of the central bank.

Table 1 Stationarity of Inflation Expectations

\begin{tabular}{l|cccc|cccc}
\hline \hline Variable & Test & $\mathrm{H}_{0}$ & $\begin{array}{c}\text { Test } \\
\text { statistic }\end{array}$ & $\begin{array}{c}1 \% \text { crit. } \\
\text { value }\end{array}$ & Test & $\mathrm{H}_{0}$ & $\begin{array}{c}\text { Test } \\
\text { statistic }\end{array}$ & $\begin{array}{c}10 \% \text { crit. } \\
\text { value }\end{array}$ \\
$\pi_{t}^{e, s}$ & DF-GLS & $\mathrm{I}(1)$ & -3.87 & -2.57 & KPSS & $\mathrm{I}(0)$ & 0.20 & 0.35 \\
\hline & & & & $\begin{array}{c}10 \% \text { crit. } \\
\text { value }\end{array}$ & & & & $\begin{array}{c}1 \% \text { crit. } \\
\text { value }\end{array}$ \\
$\pi_{t}^{e, l}$ & DF-GLS & $\mathrm{I}(1)$ & -1.82 & -2.60 & KPSS & $\mathrm{I}(0)$ & 0.37 & 0.22 \\
\hline \hline
\end{tabular}

Note: The table shows unit root test results for short-term and long-term inflation expectations. According to both tests, short-term expectations are stationary while long-term expectations appear non-stationary. The KPSS test (Kwiatkowski et al., 1992) has the null hypothesis of stationarity $(I(0))$. The DF-GLS test (Elliott et al., 1996) has the null hypothesis of a unit root $(I(0))$. The lag length is determined by the Schwarz information criterion. Because of the downward drift of long-term inflation expectations in the nineties, we allow for a trend under the alternative hypothesis.

\footnotetext{
${ }^{3}$ In addition to the results presented in Table 1 , we confirmed the robustness of the unit root test results by allowing for endogenous breaks in the deterministic terms (see Perron et al., 2006) under the alternative hypothesis. For brevity, these results are not reported but available on request.
} 
Figure 1 suggests that the volatility of inflation expectations is not constant over time. In particular, short-term inflation expectations exhibit extended periods of pronounced increases in volatility. The presence of different volatility regimes motivates the application of a heteroskedastic Markov-Switching VAR.

\section{The Anchoring of Inflation Expectations: Empirical Results}

\subsection{Specifying a Structural Markov-Switching VAR Model for Inflation Expectations}

In line with Blanchard and Quah (1989) and the stationarity properties of shortterm and long-term inflation expectations, we employ a VAR for the level of short-term and the first difference of long-term inflation expectations, i.e. $y_{t}=$ $\left(\pi_{t}^{e, s}, \Delta \pi_{t}^{e, l}\right)^{\prime}$.

The first step of our empirical analysis is to determine the order of the VAR model. The lag length $p=6$, suggested by the Schwarz information criterion, gives us virtually no autocorrelation of the reduced form residuals. In a second step, we allow for heteroskedasticity of inflation expectations by estimating Markov-Switching VAR(6) models with two and three volatility regimes. Summary statistics for estimated models are shown in Table 2. Both mod- 
els with Markov-Switching mechanism substantially outperform the standard VAR. In line with the information criterion, we proceed with the two regime model.

\begin{tabular}{|c|c|}
\hline Model & $\overline{\log L_{T}}$ \\
\hline VAR(6) & $131.816 \quad-97.460$ \\
\hline MS(2)-VAR(6) & $205.980-217.137$ \\
\hline MS(3)-VAR(6) & $214.573-194.212$ \\
\hline \multicolumn{2}{|c|}{$\begin{array}{l}\text { Note: The table shows specification } \\
\text { test results for the VAR of short- } \\
\text { term and long-term inflation expec- } \\
\text { tations. The log-likelihood and the } \\
\text { Schwarz (SC) information criterion are } \\
\text { reported. } L_{T} \text { is the likelihood function } \\
\text { and } S C=-2 \log L_{T}+\log T \times \# \text { of free } \\
\text { parameters. }\end{array}$} \\
\hline
\end{tabular}

It is important to check that the model with heteroskedasticity identifies the shocks sufficiently well. In accordance with (6), the formal condition for identification in our setup is $\lambda_{21} \neq \lambda_{22}$, which is indicated by the standard deviations reported in Table 3. Therefore, there should be sufficient separation of shocks on the basis of their volatility to ensure statistical identification and to allow to test the long-run neutrality restriction (3). Note that the estimated relative variances of structural shocks are all below one. This implies that the first regime, where variances are normalized to one, is the high volatility regime.

The estimated regime probabilities of the MS(2)-VAR(6) model are shown in Figure 2. The probabilities reflect the elevated volatility in the beginning of 1990s and 2000s, and around the global financial crisis. The second regime 
may be attributed to rather tranquil times in the economy with significantly reduced volatility of both structural shocks.

Table 3 Relative Variances of the MS(2)-SVAR(6) Model

\begin{tabular}{l|cc}
\hline \hline parameter & estimate & std.dev. \\
\hline$\lambda_{21}$ & 0.078 & 0.019 \\
$\lambda_{22}$ & 0.283 & 0.091 \\
\hline \hline
\end{tabular}

Note: The table shows the estimated relative variances of the unrestricted MS(2)-SVAR(6) model together with their standard deviations, see (6).

Figure 2 Estimated Regime Probabilities

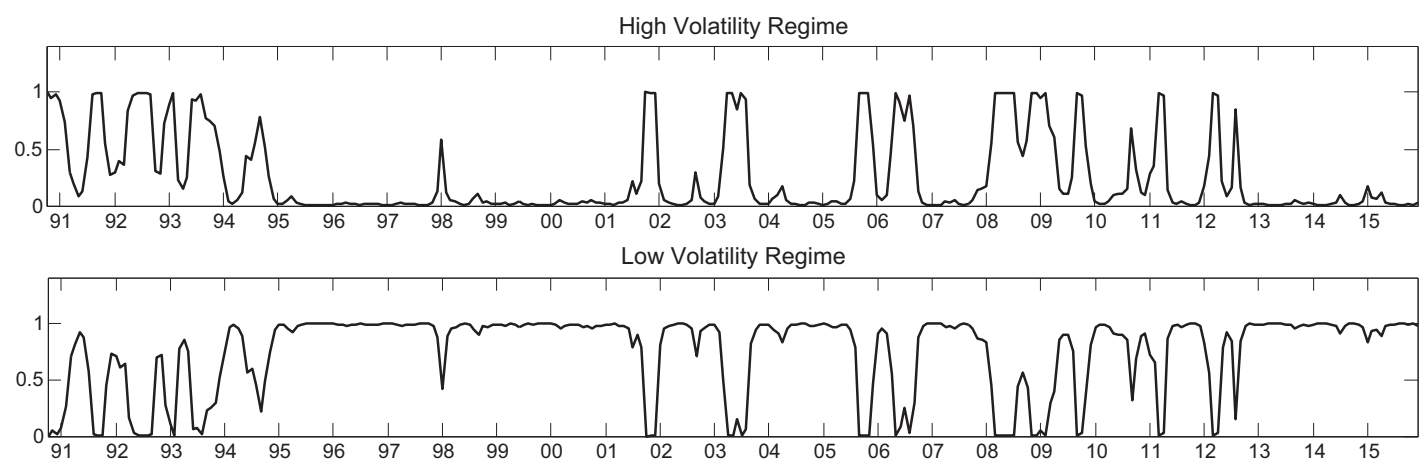

Note: Estimated regime probabilities of the MS(2)-SVAR(6) model for inflation expectations. The first regime is the high volatility regime with unit variances of shocks while the second regime is the low volatility regime with shock variances substantially below one (see Table 3).

\subsection{Testing the Long-Run Anchoring of Inflation Expectations}

The previous section showed that the structural MS(2)-VAR model of inflation expectations is already identified through changes in volatility. We will now investigate whether the shocks obtained through statistical identification can 
be given an economic interpretation as well. To this end, we add the longrun anchoring restriction introduced in section 3 to the structural MS(2)-VAR model. Since this additional restriction is overidentifying, the heteroscedasticity can be used to test the long-run anchoring of inflation expectations.

The result of the corresponding likelihood-ratio test is shown in Table 4. The test clearly supports the overidentifying long-run restriction (3), implying that macro-news shocks are long-run neutral for long-term inflation expectations. Therefore, we conclude that U.S. long-term inflation expectations are well anchored in the long run.

Table 4 Testing the Overidentifying Long-Run Anchoring Restriction

\begin{tabular}{c|c|c|cc}
\hline \hline$H_{0}$ & $H_{1}$ & $\mathrm{df}$ & LR statistic & $p$-value \\
\hline$\Xi_{\infty}$ as in (3) & unrestricted $\Xi_{\infty}$ & 1 & 0.469 & 0.493 \\
\hline \hline
\end{tabular}

Note: The table shows the results from testing the identifying longrun restriction (3) in the MS(2)-SVAR(6) model for short- and long-term inflation expectations. The alternative hypothesis is the unrestricted MS(2)-SVAR(6) model.

\subsection{The Anchoring of Inflation Expectations in the Short Run}

Let us now employ the estimated structural MS(2)-VAR(6) model with the long-run anchoring restriction to investigate the relative importance of macronews and target shocks for the variance of inflation expectations. Note that the variance decomposition of a MS-VAR model depends on the volatility regime.

Table 5 shows that, irrespective of the volatility regime, the variance of shortterm inflation expectations is virtually completely explained by macro-news 
shocks at all horizons. Therefore, as expected, the effect of target shocks on short-term inflation expectations is only small. By contrast, both types of shocks contribute to the variation of long-term inflation expectations. The relative importance of macro-news shocks for the variance of long-term inflation expectations measures the degree to which expectations are de-anchored in the short run. In the high volatility regime, the fraction of the variance of $\Delta \pi_{t}^{e, l}$ explained by macro-news shocks is $13.8 \%$ after 12 months. Therefore, although inflation expectations are anchored in the long run, the disturbing impact of macro-news shocks on long-term inflation expectations can be substantial. In the low volatility regime, the role of macro-news for long-term inflation expectations is significantly smaller. Apparently, the short-run de-anchoring of longterm inflation expectations is less severe (about $4 \%$ ) in less turbulent times.

Table 5 Forecast Error Variance Decomposition of Inflation Expectations

\begin{tabular}{|c|c|c|c|c|c|c|}
\hline \multirow{2}{*}{ Variable } & \multirow{2}{*}{ Regime } & \multirow{2}{*}{ Shock } & \multicolumn{4}{|c|}{ Horizon } \\
\hline & & & 0 & 12 & 24 & 100 \\
\hline \multirow{4}{*}{$\pi_{t}^{e, s}$} & & $\varepsilon^{1}-$ Macro-news shock & 0.994 & 0.988 & 0.988 & 0.988 \\
\hline & High volatility & $\varepsilon^{2}$ - Target shock & 0.006 & 0.012 & 0.012 & 0.012 \\
\hline & & $\varepsilon^{1}-$ Macro-news shock & 0.981 & 0.962 & 0.962 & 0.962 \\
\hline & Low volatility & $\varepsilon^{2}-$ Target shock & 0.019 & 0.038 & 0.038 & 0.038 \\
\hline \multirow{4}{*}{$\Delta \pi_{t}^{e, l}$} & & $\varepsilon^{1}-$ Macro-news shock & 0.150 & 0.138 & 0.138 & 0.138 \\
\hline & High volatility & $\varepsilon^{2}-$ Target shock & 0.850 & 0.862 & 0.862 & 0.862 \\
\hline & & $\varepsilon^{1}-$ Macro-news shock & 0.048 & 0.044 & 0.044 & 0.044 \\
\hline & Low volatility & $\varepsilon^{2}$ - Target shock & 0.952 & 0.956 & 0.956 & 0.956 \\
\hline
\end{tabular}

Note: The table shows the forecast error variance decomposition based on the MS(2)SVAR(6) model with the long-run anchoring restriction. It provides an overview on the volatility regime-dependent contributions of the macro-news shock and the target shock to the variance of short- and long-term inflation expectations. 
More information about the dynamics of inflation expectations is provided by the corresponding impulse response analysis, see Figure 3. The impulse responses show the long-run impact of target shocks on long-term inflation expectations and reflect the long-run neutrality condition of macro-news shocks. The impulse responses confirm the intuition that macro-news shocks are particularly related to short-term expectations, while long-term inflation expectations are mainly driven by target shocks. The impulse response analysis further reveals a significant short-run de-anchoring effect of a macro-news shock on long-term inflation expectations.

Figure 3 Impulse Responses of Short- and Long-Term Inflation Expectations
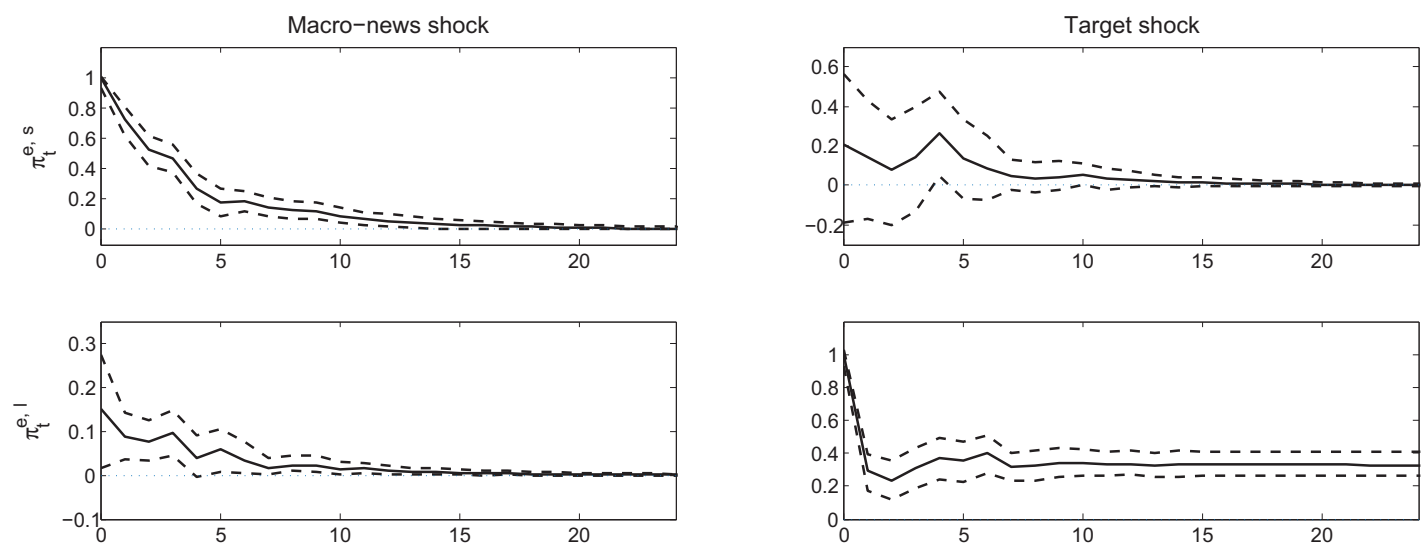

Notes: The impulse responses are based on the structural MS(2)-VAR(6) model with the longrun anchoring restriction imposed. The impulse response of $\pi_{t}^{e, l}$ is accumulated. The solid lines represent the point estimates while the dashed lines are $95 \%$ confidence intervals. The confidence intervals are computed from 1000 bootstrap replications. The shocks are scaled to have unit impact on the variables. 


\subsection{Counterfactual Analysis: The Anchored Level of Inflation Expectations}

The forecast error variance decomposition of the SVAR can be used as a measure of the average degree of the short-run de-anchoring of long-term inflation expectations over the whole sample period. For monetary policy practice, it is probably more important to what extent and in which direction inflation expectations are de-anchored in a specific time period. Put differently, to what extent is an observed change in long-term inflation expectations caused by macro-news shocks? In order to shed more light on this issue, we employ the structural VAR to perform a counterfactual analysis as follows: Suppose that from a starting point $t_{0}$ onwards, all macro-news shocks would have been zero, i.e. $\forall t>t_{0} \varepsilon_{1 t}=0$. This implies that the resulting counterfactual value of long-term inflation expectations is unaffected by macro-news and, thus, remains at its anchored level.

The recent literature has been particularly interested in the behavior of inflation expectations in the aftermath of the financial crisis. Therefore, we present a counterfactual analysis which starts with the Lehman breakdown in September 2008. The corresponding results are shown in Figure 4. Interestingly, the counterfactual level of anchored long-term inflation expectations follows the series of actual inflation expectations closely. In particular, falling from $3.2 \%$ in early 2011 to $2.7 \%$ in late 2015, both series exhibit a downward trend from 2011 onwards. This implies that the decrease of long-term inflation expectations observed in the aftermath of the financial crisis can be largely attributed to target shocks and, therefore, to downward adjustments of consumers' expectations 
about the long-run inflation target of the central bank.

Figure 4 Counterfactual Analysis: Long-Term Inflation Expectations with Zero Macro-News Shocks

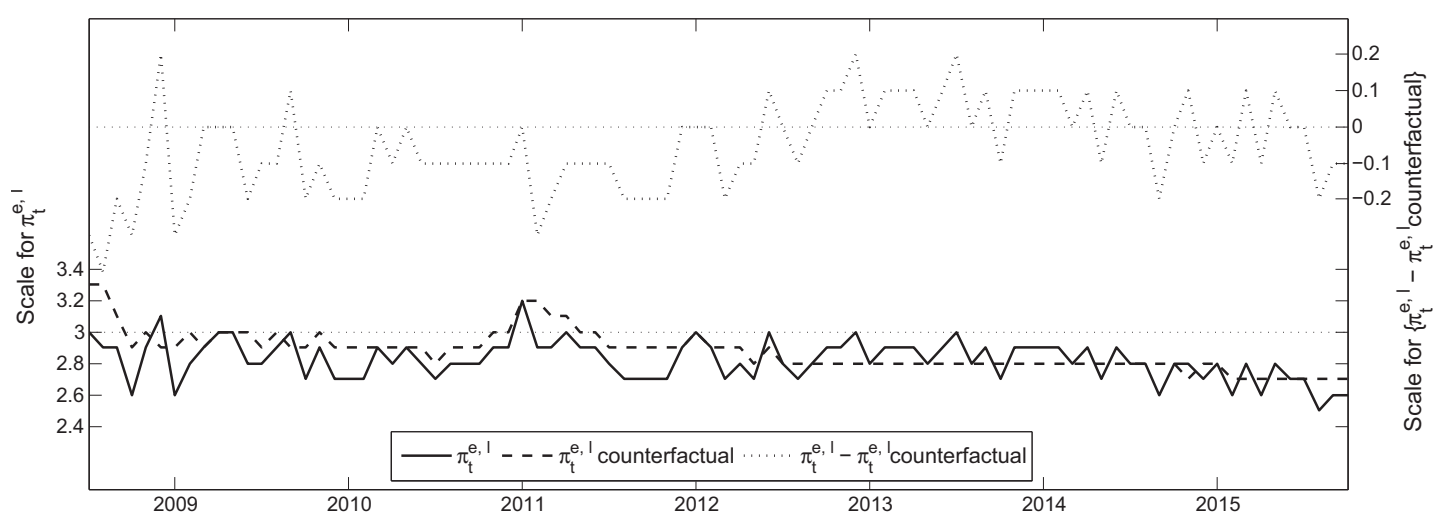

Note: The counterfactual long-term expectations series is based on the estimated structural VAR. It is assumed that all macro-news shocks are zero from October 2008 onwards. As a consequence, the counterfactual long-term inflation expectations remain at the anchored level.

\section{Conclusions}

In a perfect world where expectations are rational and the central bank is fully credible with an entirely transparent long-run inflation target, there is no reason why long-term inflation expectations should respond to macroeconomic news that have no implications for the long run. As a consequence, inflation expectations can only be seen as anchored if macro-news shocks are long-run neutral to the level of long-term inflation expectations. In contrast to macronews shocks, target shocks refer to the long-run monetary policy strategy and include news about the level of the central bank's inflation target.

This paper proposes a structural VAR analysis in order to estimate the im- 
pact of both macro-news and target shocks on inflation expectations. The validity of the identifying long-run anchoring restriction is tested by exploiting the heteroskedasticity in the expectations data. Using U.S. consumers' survey data from 1990 onwards, we find that the long-run neutrality of macronews shocks for long-term inflation expectations is compatible with the data, implying that expectations are anchored in the long run. In the short run, however, the disturbing impact of macro-news on long-term inflation expectations should not be ignored, particularly in turbulent times when the volatility of shocks is high. Counterfactual analysis suggests that target shocks indicating downward adjustments of the consumers' expectations about the central bank's inflation target contributed significantly to the observed decrease of long-term inflation expectations in the aftermath of the financial crisis.

This paper demonstrated that the structural VAR model can be a useful tool for investigating the behavior of inflation expectations. Taking into account the difference between anchoring of inflation expectations in the short and in the long run, it generalizes the prevailing approaches applied in the empirical anchoring literature. In particular, the identification of structural shocks helps to explain why inflation expectations depart from the central bank's official inflation target. While our empirical analysis uses a very parsimonious model, future research might aim at a more complete picture of the determinants of inflation expectations. Possible extensions include international spillover effects of inflation expectations (Netšunajev and Winkelmann, 2014), nonlinearities in times of undesirably low inflation (Ehrmann, 2015) as well as more macroeconomic variables and a broader spectrum of structural shocks (see e.g. Del Negro et al., 2015 and Arias et al., 2016). 


\section{References}

Arias, J., Erceg, C., and Trabandt, M. (2016). The macroeconomic risks of undesirably low inflation. European Economic Review, forthcoming.

Autrup, S. L. and Grothe, M. (2014). Economic surprises and inflation expectations: Has anchoring of expectations survived the crisis? European Central Bank Working Paper Series, 1671.

Bauer, M. D. (2015). Inflation expectations and the news. International Journal of Central Banking.

Beechey, M. J., Johannsen, B. K., and Levin, A. T. (2011). Are long-run inflation expectations anchored more firmly in the Euro area than in the United States? American Economic Journal: Macroeconomics, 3(2):pp. 104-129.

Blanchard, O. and Quah, D. (1989). The dynamic effects of aggregate demand and supply disturbances. American Economic Review, 79:655-673.

Bomfim, A. N. and Rudebusch, G. D. (2000). Opportunistic and deliberate disinflation under imperfect credibility. Journal of Money, Credit and Banking, 32(4):pp. 707-721.

Chen, W. and Netšunajev, A. (2016). On the long-run neutrality of demand shocks. Economics Letters, 139:57 - 60.

Clarida, R., Gali, J., and Gertler, M. (2000). Monetary policy rules and macroeconomic stability: Evidence and some theory. Quaterly Journal of Economics, 115(1):147.

Del Negro, M., Giannoni, M. P., and Schorfheide, F. (2015). Inflation in the great recession and new keynesian models. American Economic Journal: Macroeconomics, 7:168-196.

Dovern, J. (2015). A multivariate analysis of forecast disagreement: Confronting models of disagreement with survey data. European Economic Review, 80:16-35.

Dovern, J., Fritsche, U., and Slacalek, J. (2012). Disagreement among forecasters in G7 countries. Review of Economics and Statistics, 94(4):1081-1096. 
Easaw, J., Golinelli, R., and Malgarini, M. (2013). What determines households inflation expectations? Theory and evidence from a household survey. European Economic Review, 61:1-13.

Ehrmann, M. (2015). Targeting inflation from below: How do inflation expectations behave? International Journal of Central Banking, September:213 - 249.

Ehrmann, M., Fratzscher, M., Gürkaynak, R. S., and Swanson, E. T. (2011). Convergence and anchoring of yield curves in the euro area. The Review of Economics and Statistics, 93(1):350-364.

Elliott, G., Rothenberg, T. J., and Stock, J. H. (1996). Efficient tests for an autoregressive unit root. Econometrica: Journal of the Econometric Society, pages 813-836.

Galati, G., Poelhekke, S., and Zhou, C. (2011). Did the crisis affect inflation expectations? International Journal of Central Banking, 7(1):167-207.

Gürkaynak, R. S., Levin, A., and Swanson, E. (2010). Does inflation targeting anchor long-run inflation expectations? Evidence from the U.S., UK, and Sweden. Journal of the European Economic Association, 8(6):1208-1242.

Herwartz, H. and Lütkepohl, H. (2014). Structural vector autoregressions with Markov switching: Combining conventional with statistical identification of shocks. Journal of Econometrics.

Jochmann, M., Koop, G., and Potter, S. M. (2010). Modeling the dynamics of inflation compensation. Journal of Empirical Finance, 17(1):157 - 167.

Kwiatkowski, D., Phillips, P. C., Schmidt, P., and Shin, Y. (1992). Testing the null hypothesis of stationarity against the alternative of a unit root: How sure are we that economic time series have a unit root? Journal of econometrics, 54(1):159-178.

Lanne, M., Lütkepohl, H., and Maciejowska, K. (2010). Structural vector autoregressions with markov switching. Journal of Economic Dynamics and Control, 34(2):121-131.

Lütkepohl, H. and Netšunajev, A. (2014). Disentangling Demand And Supply Shocks In The Crude Oil Market: How To Check Sign Restrictions In Structural Vars. Journal of Applied Econometrics, 29(3):479-496. 
Mehrotra, A. N. and Yetman, J. (2014). Decaying expectations: What inflation forecasts tell us about the anchoring of inflation expectations. BIS Working Paper.

Nautz, D. and Strohsal, T. (2015). Are US inflation expectations re-anchored? Economics Letters, 127:6-9.

Netšunajev, A. and Winkelmann, L. (2014). Inflation expectations spillovers between the United States and euro area. SFB 649 Discussion Paper 2014-023.

Pagenhardt, L., Nautz, D., and Strohsal, T. (2015). The (de-) anchoring of inflation expectations: New evidence from the euro area. SFB 649 Discussion Paper.

Perron, P. et al. (2006). Dealing with structural breaks. Palgrave handbook of econometrics, 1:278-352.

Rudebusch, G. D. (2001). Is the fed too timid? monetary policy in an uncertain world. Review of Economics and Statistics, 83(2):203-217.

Schmidt, S. and Nautz, D. (2012). Central bank communication and the perception of monetary policy by financial market experts. Journal of Money, Credit and Banking, 44(2-3):323-340.

Sims, C. A. (1980). Macroeconomics and reality. Econometrica, 48:1-48.

Strohsal, T., Melnick, R., and Nautz, D. (2016). The time-varying degree of inflation expectations anchoring. Journal of Macroeconomics, 48:62-71.

Strohsal, T. and Winkelmann, L. (2015). Assessing the anchoring of inflation expectations. Journal of International Money and Finance, 50(0):33 - 48.

Yellen, J. L. (2015). Inflation dynamics and monetary policy. Speech at the Philip Gamble Memorial Lecture, University of Massachusetts, Amherst, Massachusetts, 2015-09-24. 


\section{SFB 649 Discussion Paper Series 2016}

For a complete list of Discussion Papers published by the SFB 649, please visit http://sfb649.wiwi.hu-berlin.de.

001 "Downside risk and stock returns: An empirical analysis of the long-run and short-run dynamics from the G-7 Countries" by Cathy Yi-Hsuan Chen, Thomas C. Chiang and Wolfgang Karl Härdle, January 2016.

002 "Uncertainty and Employment Dynamics in the Euro Area and the US" by Aleksei Netsunajev and Katharina Glass, January 2016.

003 "College Admissions with Entrance Exams: Centralized versus Decentralized" by Isa E. Hafalir, Rustamdjan Hakimov, Dorothea Kübler and Morimitsu Kurino, January 2016.

004 "Leveraged ETF options implied volatility paradox: a statistical study" by Wolfgang Karl Härdle, Sergey Nasekin and Zhiwu Hong, February 2016.

005 "The German Labor Market Miracle, 2003 -2015: An Assessment" by Michael C. Burda, February 2016.

006 "What Derives the Bond Portfolio Value-at-Risk: Information Roles of Macroeconomic and Financial Stress Factors" by Anthony H. Tu and Cathy Yi-Hsuan Chen, February 2016.

007 "Budget-neutral fiscal rules targeting inflation differentials" by Maren Brede, February 2016.

008 "Measuring the benefit from reducing income inequality in terms of GDP" by Simon Voigts, February 2016.

009 "Solving DSGE Portfolio Choice Models with Asymmetric Countries" by Grzegorz R. Dlugoszek, February 2016.

010 "No Role for the Hartz Reforms? Demand and Supply Factors in the German Labor Market, 1993-2014" by Michael C. Burda and Stefanie Seele, February 2016.

011 "Cognitive Load Increases Risk Aversion" by Holger Gerhardt, Guido P. Biele, Hauke R. Heekeren, and Harald Uhlig, March 2016.

012 "Neighborhood Effects in Wind Farm Performance: An Econometric Approach" by Matthias Ritter, Simone Pieralli and Martin Odening, March 2016.

013 "The importance of time-varying parameters in new Keynesian models with zero lower bound" by Julien Albertini and Hong Lan, March 2016.

014 "Aggregate Employment, Job Polarization and Inequalities: A Transatlantic Perspective" by Julien Albertini and Jean Olivier Hairault, March 2016.

014 "The Anchoring of Inflation Expectations in the Short and in the Long Run" by Dieter Nautz, Aleksei Netsunajev and Till Strohsal, March 2016. 